\title{
Erratum to: Modeling Study of Foehn Wind Events in Antarctic Peninsula with WRF Forced by CCSM
}

\author{
Chongran $\mathrm{ZHANG}^{1 *}$ and Jing $\mathrm{ZHANG}^{1,2}$ \\ 1 Applied Science and Technology Program, North Carolina A \& T State University, Greensboro, NC 27411, USA \\ 2 Department of Physics, North Carolina A \& T State University, Greensboro, NC 27411, USA \\ (Received February 17, 2019; in final form May 17, 2019) \\ Citation: Zhang, C., and J. Zhang, 2019: Erratum to: Modeling study of foehn wind events in Antarctic Peninsula \\ with WRF forced by CCSM. J. Meteor. Res., 33(3), 576-576, doi: 10.1007/s13351-019-8067-4.
}

This erratum is to report a figure error in Zhang and Zhang (2018) entitled "Modeling Study of Foehn Wind Events in Antarctic Peninsula with WRF Forced by CCSM". In Zhang and Zhang (2018), Figs. 7c, e (left panels below) should be replaced by Figs. $7^{*} \mathrm{c}$, e (right panels
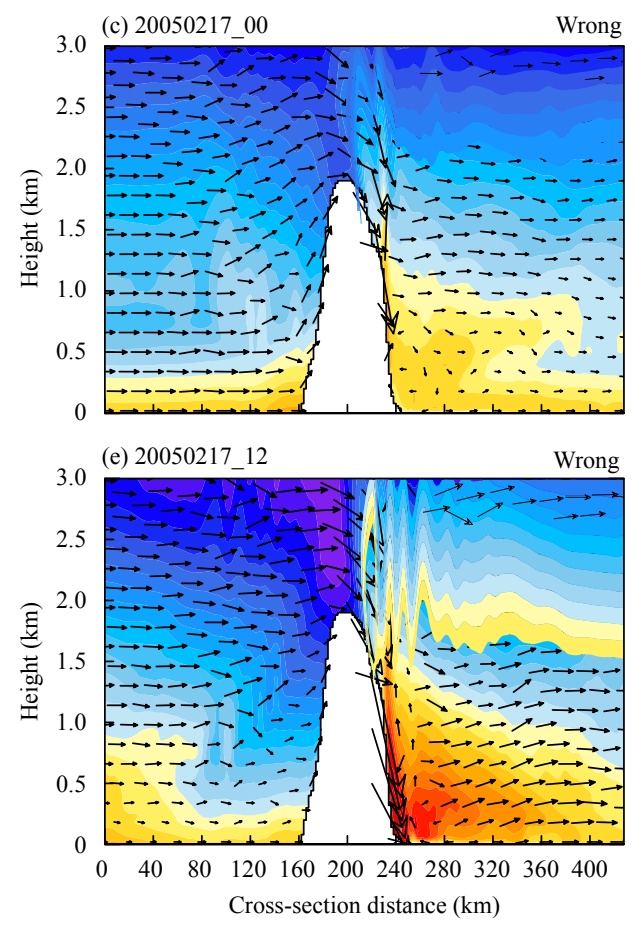

Fig. 7. (c, d) Original panles in Zhang and Zhang (2018).

\section{REFERENCES}

Zhang, C., and J. Zhang, 2018: Modeling study of foehn wind below) here.

It is important to note that the conclusions about temperature and wind vector profiles in the original paper still hold. We apologize and hope that this erratum does not reflect poorly on the paper's overall quality.

\footnotetext{
*Corresponding author: czhang@aggies.ncat.edu.

CThe Chinese Meteorological Society and Springer-Verlag Berlin Heidelberg 2019
} 